\title{
Estimation of biochemical parameters from leaf photosynthesis
}

\author{
Ken-Loong Chew ${ }^{1} \quad$ Tim Langtry $^{2} \quad$ Yakov Zinder $^{3}$ \\ Qiang $\mathrm{Yu}^{4} \quad$ Longhui $\mathrm{Li}^{5}$
}

(Received 9 January 2012; revised 23 May 2012)

\begin{abstract}
The objective of measuring leaf photosynthesis using infrared gas analysis is to determine key indicators of plant eco-physiology, including light and $\mathrm{CO}_{2}$ compensation and saturation points, and critical thresholds of temperature. These and other biochemical parameters in photosynthesis models define specific response curves of photosynthetic rate to environmental variables, such as light intensity, temperature, and $\mathrm{CO}_{2}$. Since these parameters cannot regularly be measured in the field, modellers normally adopt laboratory values as universal ones even though the values of these parameters may vary across plant species. This study investigates the identification of parameter values from data sets obtained from field measurement.
\end{abstract}

http://journal.austms.org.au/ojs/index.php/ANZIAMJ/article/view/5106 gives this article, (c) Austral. Mathematical Soc. 2012. Published June 16, 2012. ISSN 1446-8735. (Print two pages per sheet of paper.) Copies of this article must not be made otherwise available on the internet; instead link directly to this URL for this article. 


\section{Contents}

1 Introduction

C219

2 The photosynthesis model

C220

3 The parameter optimisation problem

C223

3.1 First formulation . . . . . . . . . . . . . . . C224

3.2 Second formulation . . . . . . . . . . . . . . C224

3.3 Initial parameter estimates . . . . . . . . . . . C226

4 Results

C226

5 Directions for further work

C229

A Constraint sets, parameter estimates and regression results

C230

References

$\mathrm{C} 230$

\section{Introduction}

The rate of photosynthesis is a key indicator of the effect the local environment has on an individual plant. Predicting photosynthetic rates accurately may provide insights into plant physiology by showing how the photosynthetic rate responds to changes in environmental conditions. Farquar et al. [5] introduced a seminal quantitative model of the photosynthesis rate that has been further developed by others $[1,9,4,10$, e.g.]. Gu et al. [7] discuss the difficulty of calibrating these models to data obtained from field studies. This article reports on an initial investigation of the parameter estimation problem using nonlinear optimisation combined with a Monte Carlo method for estimating confidence intervals for individual parameters. 


\section{The photosynthesis model}

The derivation of the photosynthesis model is based on two sub-models:

1. the stomatal model, describing the relation $C_{i}=C_{i}\left(C_{s}, D\right)$ among intercellular $\mathrm{CO}_{2}$ concentration $\left(\mathrm{C}_{\mathrm{i}}\right)$, atmospheric $\mathrm{CO}_{2}$ concentration at the leaf surface $\left(C_{s}\right)$ and atmospheric vapour pressure deficit $(D)$ without water stress; and

2. the biochemical model, describing the relation $P_{n}=P_{n}\left(I, T, C_{i}\right)$ between net photosynthetic rate $\left(P_{n}\right)$, light intensity $(I)$, air temperature $(T)$, and $\mathrm{C}_{i}$.

The net rate of photosynthesis is assumed to be proportional to the difference between atmospheric $\mathrm{CO}_{2}$ and intercellular $\mathrm{CO}_{2}$ :

$$
P_{n}=g_{s}\left(C_{s}-C_{i}\right),
$$

where the proportionality coefficient $g_{s}$ is stomatal conductance. Following previous work [5, 4], stomatal conductance was expressed as a function of vapour pressure deficit, ambient $\mathrm{CO}_{2}$ concentration over leaf surface and net photosynthetic rate:

$$
g_{s}=g_{0}+\frac{A P_{n} f(D)}{C_{s}-\Gamma_{*}(T)},
$$

where $f(D)=\left(1+D / D_{0}\right)^{-1}, D_{0}$ is a parameter reflecting characteristics of the response of stomata to atmospheric vapour pressure deficit, $g_{0}$ is the limiting value of stomatal conductance as $P_{n} \rightarrow 0, A$ is an empirical slope parameter and $\Gamma_{*}$ is the partial pressure of $\mathrm{CO}_{2}$ at compensation point. The latter value is temperature dependent, according to the relation [4]

$$
\Gamma_{*}(T)=\frac{O}{2 \tau(T)},
$$

where $\mathrm{O}$ is the partial pressure of oxygen,

$$
\tau(\mathrm{T})=\tau_{25} \times \tau_{\mathrm{Q} 10}^{(\mathrm{T}-25) / 10},
$$


and where $\tau_{25}$ and $\tau_{\mathrm{Q} 10}$ are empirical parameters describing relative amounts of $\mathrm{RuBP}$ bound to the carboxylase and oxygenase reactions of the RuBisCO enzyme.

According to Leuning [10], $g_{0} \geqslant 0$ and $g_{0}=0$ corresponds to there being no residual stomatal conductance. Following Yu et al. [12, 13], we assume that $g_{0}=0$. Combining (1) and (2) then gives

$$
C_{i}=C_{s}-\frac{\left(C_{s}-\Gamma_{*}(T)\right)\left(1+D / D_{0}\right)}{A},
$$

allowing the calculation of intercellular $\mathrm{CO}_{2}$ concentration from observed atmospheric $\mathrm{CO}_{2}$ concentration and vapour pressure deficit. Intercellular $\mathrm{CO}_{2}$ is one of the inputs required by the model of Farquhar et al. [5]. This is a biochemical model of photosynthesis for $\mathrm{C} 3$ plants, in which photosynthesis is expressed as a function of intercellular $\mathrm{CO}_{2}$ concentration, photosynthetical photon flux density (that is, light intensity, denoted above by I), and temperature. Farquar et al. [5] and Ball et al. [1] argued that an upper bound on the gross photosynthetic rate, $P_{n}+R_{d}$, where $R_{d}$ denotes the rate of dark respiration, may be estimated by $\min \left\{\mathrm{J}_{e}, \mathrm{~J}_{\mathrm{c}}\right\}$, where

$$
\mathrm{J}_{e}=\frac{\alpha \mathrm{AI}\left(\mathrm{C}_{\mathrm{i}}-\Gamma_{*}\right)}{\mathrm{C}_{\mathrm{i}}+2 \Gamma_{*}} \quad \text { and } \quad \mathrm{J}_{\mathrm{c}}=\frac{\mathrm{V}_{\mathrm{m}}\left(\mathrm{C}_{\mathrm{s}}-\Gamma_{*}\right)}{\mathrm{C}_{\mathrm{s}}+\mathrm{K}_{\mathrm{c}}\left(1+\mathrm{O} / \mathrm{K}_{\mathrm{o}}\right)} .
$$

Here $\mathrm{J}_{e}$ is the bound imposed on the photosynthetic rate by the production of NADPH enzymes and $\alpha$ is the quantum efficiency of NADPH production; $\mathrm{J}_{\mathrm{c}}$ is the bound on photosynthetic rate imposed by carbon reactions. This model has been adopted by many [6, 7], although Collatz et al. [4] extended the bound to $\min \left\{J_{e}, J_{c}, J_{s}\right\}$, where $J_{s}$ is the bound on the photosynthetic rate imposed by sucrose synthesis. Gu et al. [7] discussed the limitations of this extension. Collatz et al. [4] and Leuning [9, 10] revised the model of Farquhar et al. [5] to simulate the coupling of photosynthesis and transpiration.

Following Farquhar et al. [5], in this article $\min \left\{\mathrm{J}_{e}, \mathrm{~J}_{\mathrm{c}}\right\}$ is taken as an upper bound on the photosynthetic rate $P_{n}+R_{d}$. In equation (6), $V_{m}$ is the maximal 
rate of RuBisCo activity (defined below) and $\mathrm{K}_{\mathrm{c}}$ and $\mathrm{K}_{\mathrm{o}}$ are the MichaelisMenten parameters for $\mathrm{CO}_{2}$ and $\mathrm{O}_{2}$ respectively. Similarly to $\Gamma_{*}$, these are assumed to be temperature dependent, according to

$$
\mathrm{K}_{\mathrm{c}}(\mathrm{T})=\mathrm{K}_{\mathrm{c}, 25} \times \mathrm{K}_{\mathrm{c}, \mathrm{Q} 10}^{(\mathrm{T}-25) / 10} \text { and } \mathrm{K}_{\mathrm{o}}(\mathrm{T})=\mathrm{K}_{\mathrm{o}, 25} \times \mathrm{K}_{\mathrm{o}, \mathrm{Q} 10}^{(\mathrm{T}-25) / 10},
$$

where $\mathrm{K}_{\mathrm{c}, 25}, \mathrm{~K}_{\mathrm{c}, \mathrm{Q} 10}, \mathrm{~K}_{\mathrm{o}, 25}$ and $\mathrm{K}_{\mathrm{o}, \mathrm{Q} 10}$ are empirical constants. The rate of dark respiration $R_{d}$ is also temperature dependent. Following Bjorkman et al. [2], we assume

$$
R_{d}(T)=R_{d, 25} \times R_{d, Q 10}^{(T-25) / 10}\left(1+e^{1.3(T-55)}\right)^{-1},
$$

where $R_{d, 25}$ and $R_{d, Q 10}$ are parameters to be determined empirically. This model reflects a rapid decline in dark respiration at roughly $55^{\circ} \mathrm{C}$. Similarly, $\mathrm{V}_{\mathrm{m}}$ diminishes rapidly above a certain temperature, according to

$$
\mathrm{V}_{\mathrm{m}}(\mathrm{T})=\mathrm{V}_{\mathrm{m}, 25} \times \mathrm{V}_{\mathrm{m}, \mathrm{Q} 10}^{(\mathrm{T}-25) / 10}\left[1+\exp \left(\frac{-\mathrm{a}_{1}+\mathrm{b}_{1}(273+\mathrm{T})}{\mathrm{R}(273+\mathrm{T})}\right)\right]^{-1},
$$

where $V_{m, 25}$ and $V_{m, Q 10}$ are parameters which describe RuBisCo capacity, $a_{1}$ and $b_{1}$ are empirical constants, and $R$ is the universal gas constant.

Again following Farquhar et al. [5], the actual net photosynthetic rate is then estimated by the blend of the expressions for $\mathrm{J}_{e}$ and $\mathrm{J}_{c}$ represented by the smaller root of the equation

$$
\theta\left(P_{n}+R_{d}\right)^{2}-\left(J_{e}+J_{c}\right)\left(P_{n}+R_{d}\right)+J_{e} J_{c}=0,
$$

where $0 \leqslant \theta \leqslant 1$, yielding

$$
P_{n}=\frac{\left(J_{e}+J_{c}\right)-\sqrt{\left(J_{e}+J_{c}\right)^{2}-4 \theta J_{e} J_{c}}}{2 \theta}-R_{d} .
$$

Here, the case $\theta=1$ corresponds to $P_{n}+R_{d}=\min \left\{J_{e}, J_{c}\right\}$. Allowing $\theta \leqslant 1$ in effect asserts that $P_{n}+R_{d} \leqslant \min \left\{J_{e}, J_{c}\right\}$ and allows for some co-limitation between $J_{e}$ and $J_{c}$. In practice, Collatz et al. [4] reported that $\theta$ is typically close to one. 


\section{The parameter optimisation problem}

Equations (3)-(11) are used to compute $\mathrm{P}_{\mathrm{n}}$ once the embedded parameters have been determined. Values of these parameters for a particular species and local environment are determined by minimising the sum of squared differences between the observed and predicted photosynthetic rates for known input values for $\mathrm{T}, \mathrm{D}, \mathrm{I}$ and $\mathrm{C}_{\mathrm{s}}$, which we refer to in the following as variables. Thus, the model parameters are the unknowns in the optimisation problem, whereas values of the variables are known. Typically, the solution of this type of constrained optimisation problem requires iterative numerical techniques that rely on the provision of initial estimates for the values being sought.

In the remainder of this section we derive two formulations of the constrained optimisation problem, in each case identifying constraints which the identified parameter values must satisfy, and the objective function relating the predictor variable $P_{n}$ to a set of $N$ observations of photosynthesis rate $\left\{\widehat{P}_{n, j}: j=\right.$ $1, \ldots, N\}$. The optimal estimates for the parameter values are those for which the objective function, characterising the discrepancy between observed and predicted photosynthesis rates, is minimised.

The minimisation problem was solved for three different settings (see Appendix A). The first setting is specified by constraint set A, which was chosen to allow for the widest possible range of inputs in order to determine parameters applicable to a wide range of environmental situations. The second setting, specified by constraint set B, was chosen for the environmental settings reported by $\mathrm{Yu}$ et al. [12, 13]. The third setting, constraint set C, constrains parameters to ranges determined by the model of Farquhar et al. [5]. The final constraint of set $\mathrm{C}$ is based on the affinity of enzymes in response to temperature. As temperature increases the affinity between RuBisCO and $\mathrm{CO}_{2}$ falls, giving a larger $\mathrm{K}_{\mathrm{c}}$ value. Since the rate of photorespiration increases with temperature within the temperature range in which this model is applicable, this results in the affinity between $\mathrm{RuBisCO}$ and $\mathrm{O}_{2}$ rising at a rate faster than the affinity between $\mathrm{RuBisCO}$ and $\mathrm{CO}_{2}$. That is, $\mathrm{K}_{\mathrm{o}}$ rises at 
a slower rate than $\mathrm{K}_{\mathrm{c}}$ : simplifying the corresponding inequality

$$
\frac{\mathrm{d}}{\mathrm{dT}}\left(\mathrm{K}_{\mathrm{o}, 25} \mathrm{~K}_{\mathrm{o}, \mathrm{Q} 10}{ }^{(\mathrm{T}-25) / 10}\right) \leqslant \frac{\mathrm{d}}{\mathrm{dT}}\left(\mathrm{K}_{\mathrm{c}, 25} \mathrm{~K}_{\mathrm{c}, \mathrm{Q} 10}{ }^{(\mathrm{T}-25) / 10}\right),
$$

yields the final constraint in set $\mathrm{C}$.

\subsection{First formulation}

The first objective function takes the least squares optimisation form

$$
F_{1}(\boldsymbol{\beta})=\sum_{j=1}^{N}\left[P_{n}\left(\boldsymbol{x}_{j} ; \boldsymbol{\beta}\right)-\widehat{P}_{n, j}\right]^{2},
$$

where $\boldsymbol{x}_{j}=\left(\mathrm{I}, \mathrm{T}, \mathrm{C}_{\mathrm{s}}, \mathrm{D}\right)$ at the $\boldsymbol{j}$ th observation, $\boldsymbol{\beta}$ denotes the vector of parameter values to be determined, $P_{n}$ is given by (11) and $\widehat{P}_{n, j}$ is the observed net photosynthetic rate at the $j$ th observation. We seek that value of $\boldsymbol{\beta}$ which minimises the value of the objective function.

Since $P_{n}$ is given by (11), the objective function contains square roots which potentially impose problems in optimisation. To ensure that the values of $P_{n}$ are real, the discriminant of the quadratic equation (10) must be non-negative at each observation, prompting the additional constraints

$$
\left[J_{e}\left(\boldsymbol{x}_{j} ; \boldsymbol{\beta}\right)+\mathrm{J}_{\mathrm{c}}\left(\boldsymbol{x}_{j} ; \boldsymbol{\beta}\right)\right]^{2}-4 \theta \mathrm{J}_{e}\left(\boldsymbol{x}_{\mathrm{j}} ; \boldsymbol{\beta}\right) \mathrm{J}_{\mathrm{c}}\left(\boldsymbol{x}_{\mathrm{j}} ; \boldsymbol{\beta}\right) \geqslant 0, \quad j=1, \ldots, N .
$$

Even with the introduction of (13), optimisation of the objective function is a difficult task. Thus in some instances, when the inbuilt function 'FindMinimum' was used, Mathematica [8] reported complex values for $P_{n}$.

\subsection{Second formulation}

Modifications were made to the objective function (12) in order to remedy the problem identified above. In particular, we introduce intermediate variables $Y_{j}$, 
$j=1, \ldots, N$, which represent the predicted photosynthetic rate corresponding to each observation. Replacing $P_{n}$ by $Y_{j}$ in (11) and (12) yields

$$
Y_{j}+R_{d}=\frac{\left(J_{e}+J_{c}\right)-\sqrt{\left(J_{e}+J_{c}\right)^{2}-4 \theta J_{e} J_{c}}}{2 \theta}
$$

and a new objective function

$$
F_{2}(\boldsymbol{\beta})=\sum_{j=1}^{N}\left(Y_{j}-\widehat{P}_{n, j}\right)^{2},
$$

where, in addition to the constraints mentioned in previous sections, the values of $Y_{j}$ must be constrained to be the values of $P_{n}$, as defined in (11). Replacing $P_{n}$ in (10) (of which $P_{n}+R_{d}$ is the smaller root given by (11)) by $Y_{j}$, squaring and summing over all observations leads to the constraint

$$
\sum_{j=1}^{N}\left[\theta\left(Y_{j}+R_{d}\right)^{2}-\left(Y_{j}+R_{d}\right)\left(J_{e}+J_{c}\right)+J_{e} J_{c}\right]^{2} \leqslant \epsilon,
$$

where $\epsilon$ is a suitably chosen small nonnegative number. The case $\epsilon=0$ corresponds to requiring that $Y_{j}=P_{n}\left(\boldsymbol{x}_{j}, \boldsymbol{\beta}\right)$ for all $j$. In practice, if initially an optimum cannot be found by the optimisation algorithm, the value of $\epsilon$ is increased until the procedure is successful, although the difference between $Y_{j}$ and $P_{n}\left(\boldsymbol{x}_{j}, \boldsymbol{\beta}\right)$ may grow yielding a greater least squares error.

Due to the squaring operation, used to obtain (16), an additional constraint must be imposed to require that $Y_{j}+R_{d}$ corresponds to the smaller root of (10). Specifically, since the smaller root satisfies

$$
\frac{\left(\mathrm{J}_{e}+\mathrm{J}_{\mathrm{c}}\right)-\sqrt{\left(\mathrm{J}_{e}+\mathrm{J}_{\mathrm{c}}\right)^{2}-4 \theta \mathrm{J}_{e} \mathrm{~J}_{\mathrm{c}}}}{2 \theta} \leqslant \frac{\left(\mathrm{J}_{e}+\mathrm{J}_{\mathrm{c}}\right)}{2 \theta}
$$

we require $Y_{j}+R_{d} \leqslant\left(J_{e}+J_{c}\right) /(2 \theta)$ for each predicted value, or

$$
\left[Y_{j}+R_{d}\left(x_{j}, \boldsymbol{\beta}\right)-\frac{J_{e}\left(\boldsymbol{x}_{j}, \boldsymbol{\beta}\right)+J_{c}\left(\boldsymbol{x}_{j}, \boldsymbol{\beta}\right)}{2 \theta}\right] \leqslant 0, \quad j=1, \ldots, N .
$$




\subsection{Initial parameter estimates}

A set of initial parameter estimates is required for use in the iterative procedure for solving the constrained optimisation problem. Table 3 (in Appendix A) lists two sets of starting values used in the optimisation procedure. Initial parameter estimates for constraint set $\mathrm{A}$ are based on those in Collatz et al. [4], while those for constraint sets B and C were suggested by Q. Yu. The estimates for several parameters in Collatz et al. [4] are based on experiments conducted in vivo and these parameters may vary depending on the plant species. In particular, the values of the parameters $\tau_{25}, \tau_{\mathrm{Q} 10}, \mathrm{~K}_{\mathrm{c}, 25}, \mathrm{~K}_{\mathrm{c}, \mathrm{Q} 10}$, $\mathrm{K}_{\mathrm{o}, 25}, \mathrm{~K}_{\mathrm{o}, \mathrm{Q} 10}, \mathrm{R}_{\mathrm{d}, 25}, \mathrm{R}_{\mathrm{d}, \mathrm{Q} 10}, \mathrm{~V}_{\mathrm{m}, 25}$ and $\mathrm{V}_{\mathrm{m}, \mathrm{Q} 10}$ in (4) and (7)-(9) were estimated from biochemical studies on RuBisCO [11].

\section{Results}

Each of the formulations was tested using constraint sets A, B and C with the same data set. This data set contained 1,658 observations from measurements of winter wheat photosynthesis activity conducted in a controlled leaf chamber environment using a LI-6400 gas analyser [12, 13]. Note that Yu et al. [12] calculated $\mathrm{P}_{\mathrm{n}}$ using a model similar to that discussed in this article, with parameter values from previous work and field measurements $[4,10]$.

Although point estimates of the parameters can be determined by regressing against all available data, this yields no information about the precision of the estimates. Instead, a bootstrapping approach, using subsets of the available data, was used to derive point estimates for the parameters and $70 \%$ confidence intervals for these estimates, for each constraint set. In particular, a set of $\mathrm{N}=100$ observations was drawn (with replacement) at random from the available data. Regression was then applied to this sample to determine an estimated parameter vector $\hat{\boldsymbol{\beta}}$. This procedure was repeated $\mathrm{N}_{\mathrm{s}}=500$ times yielding an empirical distribution of estimated parameter vectors with mean $\overline{\boldsymbol{\beta}}$. The sample standard deviation $\boldsymbol{\sigma}_{\widehat{\boldsymbol{\beta}}}$ and an estimated 
Table 1: Comparison of measured and predicted photosynthetic rates.

\begin{tabular}{llll}
$\left(\mathrm{F}_{\mathrm{k}}, \mathrm{S}\right)$ & Intercept & Slope & $\mathrm{F}_{1}\left(\overline{\boldsymbol{\beta}}_{(\mathrm{k}, \mathrm{S})}\right)$ \\
\hline$\left(\mathrm{F}_{1}, \mathrm{~A}\right)$ & -0.57 & 1.09 & $6.51 \times 10^{4}$ \\
$\left(\mathrm{~F}_{1}, \mathrm{~B}\right)$ & -5.7 & 1.06 & $1.53 \times 10^{5}$ \\
$\left(\mathrm{~F}_{1}, \mathrm{C}\right)$ & -5.0 & 0.0051 & $7.34 \times 10^{5}$ \\
$\left(\mathrm{~F}_{2}, \mathrm{~A}\right)$ & 0.66 & 0.15 & $3.23 \times 10^{5}$ \\
$\left(\mathrm{~F}_{2}, \mathrm{~B}\right)$ & 6.5 & 0.95 & $1.78 \times 10^{5}$ \\
$\left(\mathrm{~F}_{2}, \mathrm{C}\right)$ & 3.1 & 0.82 & $4.38 \times 10^{4}$ \\
\hline
\end{tabular}

$70 \%$ confidence interval for $\overline{\boldsymbol{\beta}}$ were then computed following the procedure of Buckland [3].

The photosynthesis model (3)-(11) with parameter vector $\overline{\boldsymbol{\beta}}$ was then used to predict the full set of observed data, yielding a set $\left.\left\{\mathrm{P}_{n}\left(\boldsymbol{x}_{j}, \overline{\boldsymbol{\beta}}\right), \widehat{P}_{n, j}\right)\right\}$ of pairs of observed and predicted rates. Simple linear regression was then applied to this set: a desirable regression line has intercept and slope close to 0 and 1 , respectively.

Table 1 lists the intercept and slope of the regression line for each combination $\left(F_{k}, S\right)$ of objective function $F_{k}$ and constraint set $S$, and the value of the first objective function $\boldsymbol{F}_{1}\left(\overline{\boldsymbol{\beta}}_{(k, S)}\right)$ where $\overline{\boldsymbol{\beta}}_{(k, S)}$ is the estimated parameter vector for $F_{k}$ and $S$. Four combinations appear to yield plausible models although there was still substantial variation in the estimates of individual parameters across these models. Figures 1-3 plot the observed rate versus predicted rate for each observation, for each objective function and constraint set using the parameter estimates $\overline{\boldsymbol{\beta}}_{(\mathrm{k}, \mathrm{S})}$. The horizontal clumping evident in some graphs is a feature that merits further investigation. Table 4 (in Appendix A) details the confidence intervals corresponding to parameter estimates for $F_{2}$ under constraint set $\mathrm{C}$, the combination yielding the least value of $F_{1}$. It is noteworthy that even for this model, there is a significant variation in precision across the individual parameter estimates. 
$(\mathrm{F} 1, \mathrm{~A})$

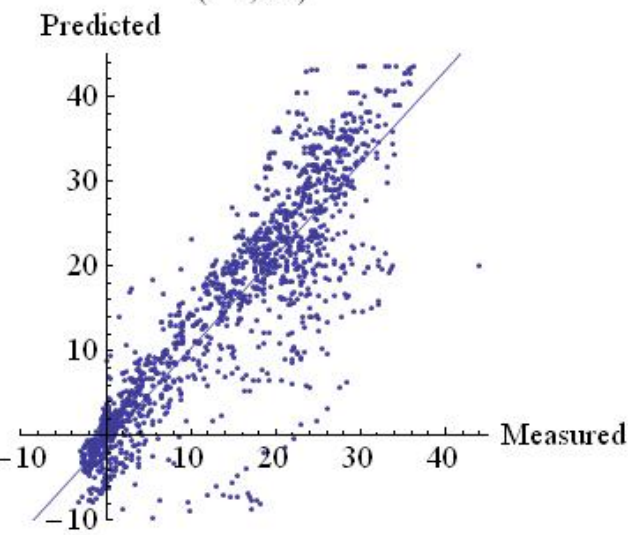

(F2, A)

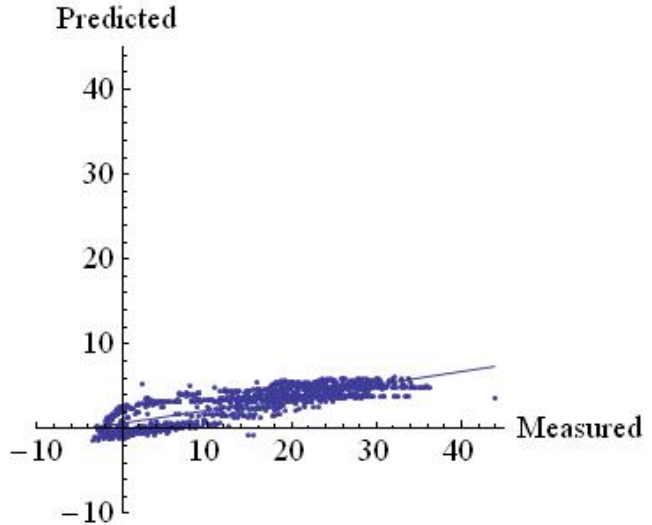

Figure 1: Measured versus predicted photosynthetic rates $\left(\mu \mathrm{mol} \mathrm{m}^{-2} \mathrm{~s}^{-1}\right)$ for constraint set A using parameters $\bar{\beta}$ from (left to right) $F_{1}, F_{2}$.

(F1, B)

Predicted

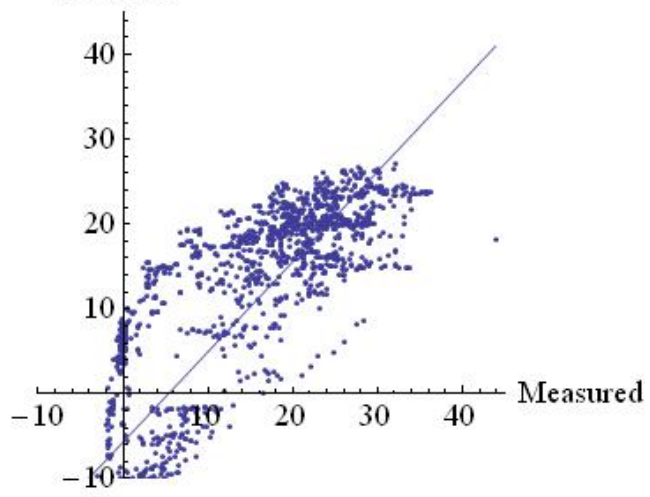

(F2, B)

\section{Predicted}

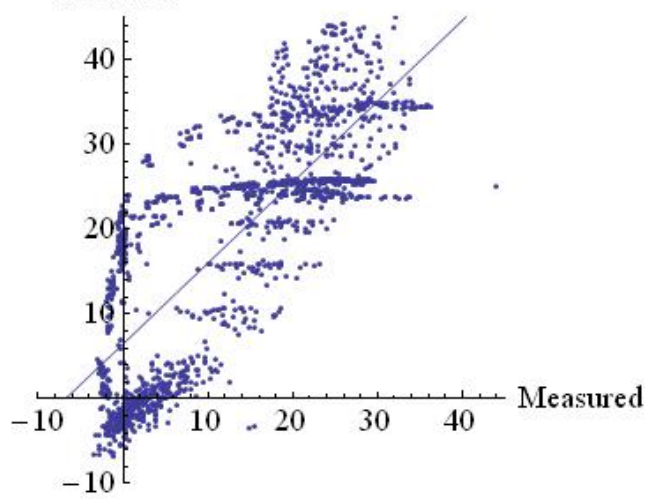

Figure 2: Measured versus predicted photosynthetic rates $\left(\mu \mathrm{mol} \mathrm{m}^{-2} \mathrm{~s}^{-1}\right)$ for constraint set $B$ using parameters $\bar{\beta}$ from (left to right) $F_{1}, F_{2}$. 
$(\mathrm{F} 1, \mathrm{C})$

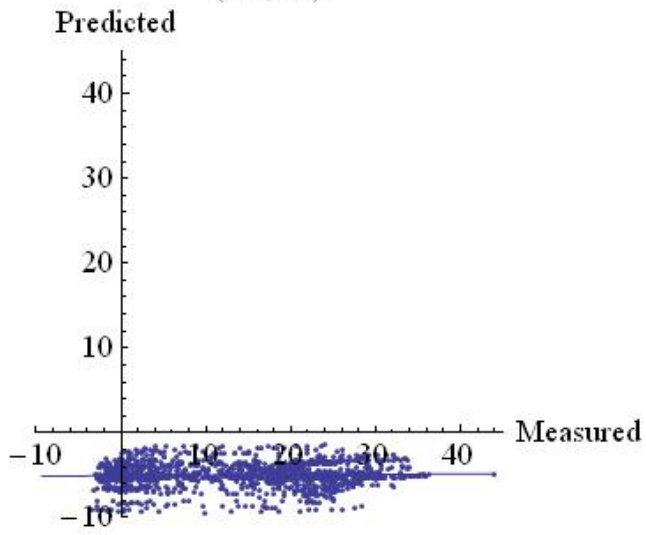

$(\mathrm{F} 2, \mathrm{C})$

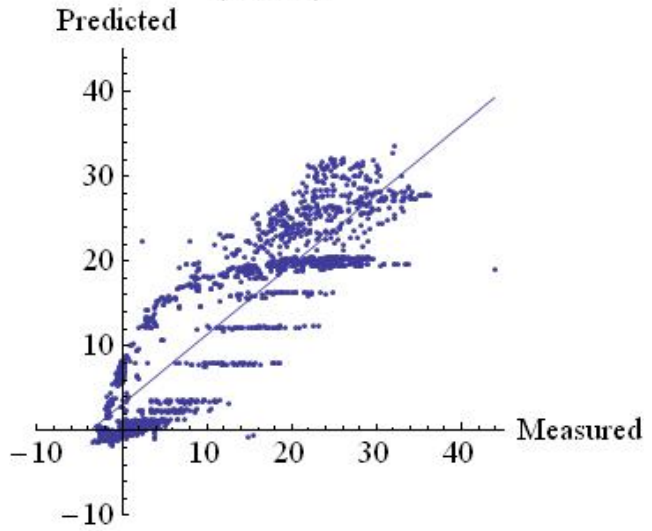

Figure 3: Measured versus predicted photosynthetic rates $\left(\mu \mathrm{mol} \mathrm{m}^{-2} \mathrm{~s}^{-1}\right)$ for constraint set $\mathrm{C}$ using parameters $\bar{\beta}$ from (left to right) $F_{1}, F_{2}$.

\section{Directions for further work}

The results of computational experiments suggest that the problem is very sensitive to variations in the input variables' values and initial estimates of parameters. The nonlinearity of the model with possible multiple local minima of the objective function also contributes to the difficulty of determination of parameters' values. This suggests that the model's performance may be improved when it is calibrated to data with relatively narrow ranges of variable values, and its application restricted to correspondingly narrow ranges. For example, we observed that the high values of $F_{1}$, indicating poor performance for $\left(F_{1}, C\right)$, are significantly improved by changing the initial estimate of $b_{1}$.

Further work remains to be done to enhance the optimisation procedure and to refine the selection of constraints and initial values on both practical and theoretical grounds. Another area for attention is the method for choosing $\overline{\boldsymbol{\beta}}$ in particular the treatment of outlier parameter vectors that may arise during the bootstrapping procedure. 


\section{A Constraint sets, parameter estimates and regression results}

The constraints of Table 2 in set A are chosen to allow for the widest possible range of input variables in order to determine parameters applicable to a wide range of environmental situations. Those in set $\mathrm{B}$ are formulated specifically for the winter wheat species, with $C_{0}$ defined as $C_{0}=K_{c}\left(1+O / K_{o}\right)$. Set $\mathrm{C}$ is based on theoretical limitations. The constraint on $\alpha$ is based on NADPH production, described in Collatz et al. [4]. The constraints in set C on $V_{m, Q 10}$ and $R_{d, Q 10}$ ensure that $V_{m}$ and $R_{d}$ increase with temperature. The constraint on $\tau$ ensures that the relative binding of $\mathrm{RuBP}$ to the carboxylase and oxygenase reactions of $\mathrm{RuBisCO}$ at compensation point decreases with temperature. Set $\mathrm{C}$ contains one final constraint not listed in Table 2, that is, $0 \leqslant \mathrm{~K}_{0,25} \frac{\log \mathrm{K}_{\mathrm{o}, \mathrm{Q} 10}}{10} \times \mathrm{K}_{\mathrm{o}, \mathrm{Q} 10}{ }^{(\mathrm{T}-25) / 10} \leqslant \mathrm{~K}_{\mathrm{c}, 25} \frac{\log \mathrm{K}_{\mathrm{c}, \mathrm{Q} 10}}{10} \times \mathrm{K}_{\mathrm{c}, \mathrm{Q} 10}{ }^{(\mathrm{T}-25) / 10}$.

Table 3 lists initial parameter estimates used in the optimisation.

Table 4 gives regression results for $\mathrm{F}_{2}$ under constraint set $\mathrm{C}$.

\section{References}

[1] J. T. Ball, I. E. Woodrow, and J. A. Berry. A model predicting stomatal conductance and its contribution to the control of photosynthesis under different environmental conditions. In M. Nijhoff, editor, Progress in photosynthesis research, pages 221-224. Kluwer Academic Publishers, 1986. C219, C221

[2] O. Bjorkman, M. R. Badger, and P. A. Armond. Response and adaptation of photosynthesis to high temperatures. In N. C. Turner and C. J. Kramer, editors, Adaptation of plants to water and high temperature stress, pages 233-249. Wiley-Interscience, New York, 1980. C222 
Table 2: Additional constraint sets.

\begin{tabular}{|c|c|c|c|c|c|c|c|}
\hline constraint on & $\begin{array}{r}\mathrm{Se} \\
\mathrm{bo} \\
\text { lower }\end{array}$ & $\begin{array}{l}\text { A } \\
\text { und } \\
\text { upper }\end{array}$ & $\begin{array}{r}\text { Se } \\
\text { bo } \\
\text { lower }\end{array}$ & $\begin{array}{c}\text { B } \\
\text { and } \\
\text { upper }\end{array}$ & $\begin{array}{r}\mathrm{Se} \\
\mathrm{bo} \\
\text { lower }\end{array}$ & $\begin{array}{l}\mathrm{t} C \\
\text { und } \\
\text { upper }\end{array}$ & Units \\
\hline$\alpha$ & & 0.5 & 0.02 & 0.2 & 0 & 0.125 & \\
\hline $\mathrm{D}_{0}$ & 0 & & 0.5 & 2.5 & 0 & & \\
\hline$A$ & 0 & & 5 & 10 & 0 & & \\
\hline$a_{1}$ & 0 & & 200 & 220 & 0 & & $\mathrm{KJmol}^{-1}$ \\
\hline$b_{1}$ & 0 & & 700 & 710 & 0 & & $\mathrm{Jmol}^{\circ} \mathrm{K}$ \\
\hline$\tau_{25}$ & 0 & & 0 & & 0 & & \\
\hline$\tau_{\mathrm{Q} 10}$ & 0 & & 0 & & 0 & 1 & \\
\hline $\mathrm{K}_{\mathrm{c}, 25}$ & 0 & & 0 & & 0 & & $\mathrm{~Pa}$ \\
\hline $\mathrm{K}_{\mathrm{c}, \mathrm{Q} 10}$ & 0 & & 0 & & 1 & & \\
\hline $\mathrm{K}_{\mathrm{o}, 25}$ & 0 & & 0 & & 0 & & $\mathrm{KPa}$ \\
\hline $\mathrm{K}_{\mathrm{o}, \mathrm{Q} 10}$ & 0 & & 0 & & 1 & & \\
\hline$V_{m, 25}$ & 0 & & 0 & & 0 & & $\mu \mathrm{mol} \mathrm{m}{ }^{-2} \mathrm{~s}^{-1}$ \\
\hline$V_{m, Q 10}$ & 0 & & 1.5 & 2.5 & 1 & & \\
\hline $\mathrm{V}_{\mathrm{m}}(\mathrm{T})$ & & & 40 & 80 & & & $\mu \mathrm{mol} \mathrm{m}{ }^{-2} \mathrm{~s}^{-1}$ \\
\hline $\mathrm{R}_{\mathrm{d}, 25}$ & 0 & & 0 & & 0 & & $\mu \mathrm{mol} \mathrm{m}{ }^{-2} \mathrm{~s}^{-1}$ \\
\hline$R_{d, Q 10}$ & 0 & & 0 & & 1 & & \\
\hline$R_{d}(T)$ & & & & 4 & & & $\mu \mathrm{mol} \mathrm{m}{ }^{-2} \mathrm{~s}^{-1}$ \\
\hline$\theta$ & 0 & 1 & 0 & 1 & 0 & 1 & \\
\hline $\mathrm{J}_{\mathrm{c}}\left(\mathrm{I}, \mathrm{T}, \mathrm{C}_{\mathrm{s}}, \mathrm{D}\right)$ & & & 10 & 40 & & & $\mu \mathrm{mol} \mathrm{m}{ }^{-2} \mathrm{~s}^{-1}$ \\
\hline$\Gamma_{*}(\mathrm{~T})$ & & & 0 & 10 & & & $\mu \mathrm{mol} \mathrm{m}{ }^{-2} \mathrm{~s}^{-1}$ \\
\hline $\mathrm{C}_{0}(\mathrm{~T})$ & & & 5 & 10 & & & \\
\hline
\end{tabular}


Table 3: Sets of initial parameter estimates used in the optimisation procedure. The letter "c" preceding the value indicates that the value of the parameter $\mathrm{O}$ was held constant.

\begin{tabular}{lcc}
\hline $\begin{array}{l}\text { Initial } \\
\text { estimate }\end{array}$ & $\begin{array}{c}\text { Constraint } \\
\text { Set A }\end{array}$ & $\begin{array}{c}\text { Constraint } \\
\text { Sets B, C }\end{array}$ \\
\hline $\mathrm{O}$ & $\mathrm{c}(20.9)$ & $\mathrm{c}(20.9)$ \\
$\alpha$ & 0.0688 & 0.04 \\
$\mathrm{D}_{0}$ & 1.6 & 1.5 \\
$\mathrm{~A}$ & 8. & 8. \\
$\mathrm{a}_{1}$ & 200. & 220. \\
$\mathrm{~b}_{1}$ & 632.7 & 703. \\
$\tau_{25}$ & 2600. & 2600. \\
$\tau_{\mathrm{Q} 10}$ & 0.57 & 0.57 \\
$\mathrm{~K}_{\mathrm{c}, 25}$ & 30. & 30. \\
$\mathrm{~K}_{\mathrm{c}, \mathrm{Q} 10}$ & 2.1 & 2.1 \\
$\mathrm{~K}_{\mathrm{o}, 25}$ & 30. & 30. \\
$\mathrm{~K}_{\mathrm{o}, \mathrm{Q} 10}$ & 1.2 & 1.2 \\
$\mathrm{~V}_{\mathrm{m}, 25}$ & 22. & 55. \\
$\mathrm{~V}_{\mathrm{m}, \mathrm{Q} 10}$ & 2. & 2. \\
$\mathrm{R}_{\mathrm{d}, 25}$ & 3. & 3. \\
$\mathrm{R}_{\mathrm{d}, \mathrm{Q} 10}$ & 2. & 2. \\
$\theta$ & 0.95 & 0.9 \\
\hline
\end{tabular}


Table 4: Point estimates and estimated $70 \%$ confidence intervals for parameter values using $F_{2}$ under constraint set $C$.

\begin{tabular}{lccc} 
& $\overline{\boldsymbol{\beta}}_{(2, \mathrm{C})}$ & $\boldsymbol{\sigma}_{\hat{\boldsymbol{\beta}}_{(2, \mathrm{C})}}$ & Est. $70 \% \mathrm{CI}\left(\overline{\boldsymbol{\beta}}_{(2, \mathrm{C})}\right)$ \\
\hline$\alpha$ & 0.0230 & 0.0152 & {$[0.0152,0.0265]$} \\
$\mathrm{D}_{0}$ & 10.23 & 14.49 & {$[1.52,14.55]$} \\
$\mathrm{A}$ & 2.46 & 1.71 & {$[1.34,3.74]$} \\
$\mathrm{a}_{1}$ & 219.45 & 10.68 & {$[220 ., 220]$.} \\
$\mathrm{b}_{1}$ & 696.61 & 34.43 & {$[691.63,703.95]$} \\
$\tau_{25}$ & 2622.18 & 310.99 & {$[2600,, 2600.02]$} \\
$\tau_{\mathrm{Q} 10}$ & 0.594 & 0.270 & {$[0.38,0.98]$} \\
$\mathrm{K}_{\mathrm{c}, 25}$ & 52.83 & 74.06 & {$[33.75,45.62]$} \\
$\mathrm{K}_{\mathrm{c}, \mathrm{Q} 10}$ & 1.63 & 1.32 & {$[1.00,2.46]$} \\
$\mathrm{K}_{\mathrm{o}, 25}$ & 21.90 & 6.17 & {$[17.76,27.42]$} \\
$\mathrm{K}_{\mathrm{o}, \mathrm{Q} 10}$ & 1.28 & 0.806 & {$[1.00,1.43]$} \\
$\mathrm{V}_{\mathrm{m}, 25}$ & 43.44 & 20.60 & {$[29.41,54.76]$} \\
$\mathrm{V}_{\mathrm{m}, \mathrm{Q} 10}$ & 1.45 & 0.414 & {$[1.15,1.71]$} \\
$\mathrm{R}_{\mathrm{d}, 25}$ & 1.06 & 1.06 & {$[0 ., 2.39]$} \\
$\mathrm{R}_{\mathrm{d}, \mathrm{Q} 10}$ & 1.22 & 0.333 & {$[1.00,1.56]$} \\
$\theta$ & 0.946 & 0.156 & {$[0.95,1.00]$} \\
\hline
\end{tabular}

[3] S. T. Buckland. Monte Carlo confidence intervals. Biometrics, 40:811-817, 1984. doi:10.2307/2530926 C227

[4] G. J. Collatz, J. T. Ball, C. Grivet, and J. A. Berry. Physiological and environmental regulation of stomatal conductance, photosynthesis and transpiration: a model that includes a laminar boundary layer. Agricultural and Forest Meteorology, 54(2-4):107-136, 1991. doi:10.1016/0168-1923(91)90002-8, C219, C220, C221, C222, C226, C230

[5] G. D. Farquhar, S. von Caemmerer, and J. A. Berry. A biochemical model of photosynthetic $\mathrm{CO}_{2}$ assimilation in leaves of $\mathrm{C} 3$ species. Planta, 149:78-90, 1980. doi:10.1007/BF00386231, C219, C220, C221, 


\section{C222, C223}

[6] G. D. Farquhar, S. von Caemmerer, and J. A. Berry. Models of photosynthesis. Plant Physiology, 125:42-45, 2001. doi:10.1104/pp.125.1.42 C221

[7] L. Gu, S. G. Pallardy, K. Tu, B. E. Law, and S. D. Wullschleger. Reliable estimation of biochemical parameters from C3 leaf photosynthesis - intercellular carbon dioxide response curves. Plant, Cell and Environment, 33:1852-1874, 2010. doi:10.1111/j.1365-3040.2010.02192.x C219, C221

[8] Wolfram Research Inc. Mathematica. Wolfram Research, Inc., Champaign, Illinois, Version 8.0, 2010. C224

[9] R. Leuning. Modelling stomatal behaviour and photosynthesis of eucalyptus grandis. Australian Journal of Plant Physiology, 17:159-175, 1990. doi:10.1071/PP9900159 C219, C221

[10] R. Leuning. A critical appraisal of a combined stomatal-photosynthesis model for C3 plants. Plant, Cell and Environment, 18(4):339-355, 1995. doi:10.1111/j.1365-3040.1995.tb00370.x C219, C221, C226

[11] I. E. Woodrow and J. A. Berry. Enzymatic regulation of photosynthetic $\mathrm{CO}_{2}$ fixation in $\mathrm{C} 3$ plants. Annual Review of Plant Physiology and Plant Molecular Biology, 39:533-594, 1988. doi:10.1146/annurev.pp.39.060188.002533 C226

[12] Q. Yu, Y. Liu, J. Liu, and T. Wang. Simulation of leaf photosynthesis of winter wheat on Tibetan Plateau and in North China Plain. Ecological Modelling, 155(2-3):205-216, 2002. doi:10.1016/S0304-3800(02)00123-0 C221, C223, C226

[13] Q. Yu, Y. Zhang, Y. Liu, and P. Shi. Simulation of the stomatal conductance of winter wheat in response to light, temperature and $\mathrm{CO}_{2}$ changes. Annals of Botany, 93:435-441, 2004. doi:10.1093/aob/mch023 C221, C223, C226 


\section{Author addresses}

1. Ken-Loong Chew, School of Mathematical Sciences, Faculty of Science, University of Technology, Sydney, PO Box 123 Broadway, NSW 2007, Australia.

2. Tim Langtry, School of Mathematical Sciences, Faculty of Science, University of Technology, Sydney, PO Box 123 Broadway, NSW 2007, Australia.

3. Yakov Zinder, School of Mathematical Sciences, Faculty of Science, University of Technology, Sydney, PO Box 123 Broadway, NSW 2007, Australia.

4. Qiang Yu, Plant Functional Biology \& Climate Change Cluster, University of Technology, Sydney, PO Box 123 Broadway, NSW 2007, Australia.

5. Longhui Li, Plant Functional Biology \& Climate Change Cluster, University of Technology, Sydney, PO Box 123 Broadway, NSW 2007, Australia. 